\title{
Clinicopathological correlation of abdominal hysterectomy
}

\author{
Tara Manandhar*, Sarita Sitaula, Baburam Dixit Thapa, Ajay Agrawal
}

Department of Obstetrics and Gynecology, B. P. Koirala Institute of Health Sciences, Dharan, Sunsari, Nepal

Received: 26 August 2020

Accepted: 01 October 2020

\section{*Correspondence:}

Dr. Tara Manandhar,

E-mail: tara2073m@hotmail.com

Copyright: ( ) the author(s), publisher and licensee Medip Academy. This is an open-access article distributed under the terms of the Creative Commons Attribution Non-Commercial License, which permits unrestricted non-commercial use, distribution, and reproduction in any medium, provided the original work is properly cited.

\section{ABSTRACT}

Background: Hysterectomy is the most common gynaecological procedure performed worldwide. Abdominal hysterectomy remains the most common approach though recently there has been preference towards laparoscopic hysterectomy. Fibroid uterus is the most common indication for hysterectomy followed by pelvic organ prolapse, benign ovarian tumour and abnormal uterine bleeding. The objective of this study was to analyse the indication, outcome and correlate the clinical indication with the histopathological diagnosis.

Methods: This study was conducted in the Department of Obstetrics and Gynaecology, B. P. Koirala Institute of Health Sciences, from January 2017 to December 2019. This is a descriptive analysis of the patients who had undergone abdominal hysterectomy during the study period.

Results: A total of 801 patients underwent abdominal hysterectomy and the most common indication was fibroid uterus $(\mathrm{n}=391,48.81 \%)$, followed by abnormal uterine bleeding. The total complication rate was $3.24 \%(\mathrm{n}=26)$ and we had one $(0.1 \%)$ mortality. Histopathological analysis of the specimen revealed leiomyoma $(54.43 \%)$ as the most common finding. The clinical indication and histopathological diagnosis matched in $373(86.94 \%)$ patients.

Conclusions: Abdominal hysterectomy is the most common approach and it is associated with risk of complications, so the indication for hysterectomy should be adequately evaluated. With the improvement in the different organpreserving options, hysterectomy in benign disease should only be opted when all the other conservative options fails.

Keywords: Abdominal hysterectomy, Gynaecology, Leiomyoma

\section{INTRODUCTION}

Hysterectomy is the most common surgery performed by the gynaecologist and it is the second most common surgical procedure performed among the women. ${ }^{1,2}$ It is a procedure whereby the uterus is removed using any of the various approaches either via abdominal or vaginal or endoscopic surgery for different benign or malignant conditions of female genital tract. ${ }^{2-4}$ The surgical approach depends on the surgeon's preferences and experience, indications for surgery, nature of diseases and the patient characteristics and concomitant procedures. Rate of hysterectomy varies from one country to another; the rate of hysterectomy is 2.13-3.62/1000 in Germany and 5.4/1000 in United States. ${ }^{5}$ In the study from Denmark, total of 154,882 hysterectomies were performed for benign conditions from year 1977 to $2009 .{ }^{6}$

Leiomyoma, abnormal uterine bleeding (AUB), pelvic organ prolapse and benign ovarian tumours are some of the commonest benign conditions where hysterectomy is indicated. The malignant indication of hysterectomy includes cervical cancers, ovarian cancers, cancer endometrium. Sometimes, it is performed for pre-invasive conditions of cervix and endometrium, and sometimes pregnancy related complications even can lead to hysterectomy. $3,^{6-8}$ Vaginal hysterectomy (VH) is the most recommended approach followed by minimal invasive approach, however choice of technique can be influenced by many factors like the size and shape of the uterus, extend of extra-uterine diseases, accessibility of the uterus, 
experience of the surgeon and so on. $\mathrm{VH}$ is not always feasible and minimal invasive approach is technically demanding. ${ }^{4,9-11}$ Therefore, though recently there has been inclining toward $\mathrm{VH}$ and minimal invasive approach, abdominal hysterectomy is still the most common approach. ${ }^{12-14}$

Uterus is an organ of self-being and has medical, sexual and emotional significance to women. A study from United States found that as high as $70 \%$ hysterectomies were inappropriately selected. ${ }^{15}$ Therefore hysterectomy should always be justified and should only be opted as last resort when all the other organ preserving measures fails. ${ }^{15,16}$ The aim of this study was to describe the indications, correlate the preoperative diagnosis with histopathological diagnosis and outcome of abdominal hysterectomy.

\section{METHODS}

This study is a descriptive study carried out at B. P. Koirala Institute of Health Sciences, Dharan, Nepal, from January 2017 to December 2019. Ethical clearance was obtained from the institutional review board before the start of the study. All the patients who had undergone abdominal hysterectomy at BPKIHS during the study period were included in the study. Hysterectomy done outside and referred to BPKIHS for various other reasons, hysterectomy done by other approach ( $\mathrm{VH}$ or minimal invasive hysterectomy), hysterectomy done for malignancy and emergency hysterectomy were excluded from the study. Case record of all the patient were reviewed and patient's demography, indication of surgery, complication and mortality were noted. Abdominal hysterectomy included total abdominal hysterectomy (TAH), TAH with bilateral salpingectomy or bilateral salpingo-oophorectomy (BSO). All the histopathological diagnosis was noted and was compared with the preoperative diagnosis to see the accuracy and justify the need of hysterectomy.

All the data were in initially entered in the excel sheet and finally converted and analysed using statistical package for the social sciences (SPSS) 21.0 IBM. Categorical variables were compared using the Fischer exact test (2 sided). Significant was set at $\mathrm{p}<0.05$.

\section{RESULTS}

During the study period of three years, we performed 801 (70.8\% of total hysterectomy) abdominal hysterectomy for benign diseases of female genital tract. The means age of these patients was $46.45 \pm 8.39$ standard deviation (SD) years ranging from 26-82 years and the maximum number of hysterectomy was done in the age group between 41-50 years $(n=407,50.81 \%)$. TAH with bilateral salpingooophorectomy (TAH with BSO) was the most common abdominal hysterectomy $(n=638,79.65 \%)$, and it was mostly performed in the patients more than 40 years age $(n=536,84.01 \%)$ (Table 1). Fibroid uterus was the most common indication for hysterectomy $(n=391,48.81 \%)$, followed by adnexal mass and abnormal uterine bleeding (Figure 1). These three were the major indications $(n=710$, $88.63 \%$ ) for abdominal hysterectomy. The less common indication included abdominopelvic mass $(n=49,6.12 \%)$, adenomyosis $(\mathrm{n}=28,3.5 \%)$ and endometrial hyperplasia $(\mathrm{n}=9,1.12 \%)$.

The total complication rate was $3.24 \%(n=26)$, out of with $13(50 \%)$ had intraoperative and rest had post-operative complications. Thirteen patients had iatrogenic bowel injury $(n=9,1.12 \%)$ and bladder injury $(n=4,0.5 \%)$ during the surgery (Table 2). All the injuries were detected intraoperatively. All these patients underwent primary repair and had uneventful recovery, expect for one patient who had sigmoid injury requiring sigmoid colostomy. There were one $(0.1 \%)$ mortality. The patient had rupture ovarian dermoid and died postoperative due to septicaemia.

Histopathological analysis of the specimen revealed benign lesion in $776(96.87 \%)$ patients and the remaining $25(3.12 \%)$ patients operated for benign condition had malignancy. Leiomyoma $(n=436,54.43 \%)$ was the most common histopathological finding followed by benign ovarian tumour $(n=210,26.22 \%)$, adenomyosis $(n=92$, $11.49 \%)$ and endometriosis $(\mathrm{n}=10,1.25 \%)$. Mature cystic teratoma $(n=87,41.42 \%)$ was the most common benign ovarian tumour, followed by endometriosis $(n=41$, $19.52 \%)$, haemorrhagic cyst $(n=28,13.33 \%)$ and serous cystadenoma $(n=27,12.85 \%)$. Twenty five patients operated for benign disease had malignancy on the histopathological examination and most of them had ovarian carcinoma $(n=15,60 \%)$ (Table 3$)$.

The patients who underwent hysterectomy for symptomatic fibroid, $350(89.51 \%)$ had histopathological diagnosis as leiomyoma and remaining 41 (10.48\%) patients revealed to have alternative diagnosis. Adenomyosis $(n=24,6.1 \%)$, was the most common unexpected histopathological diagnosis operated for fibroid disease and in seven $(1.7 \%)$ patients who were operative for fibroid disease had malignant disease on histopathological examination (Table 4).

Similarly, 22 patients operated for adenomyosis had leiomyoma in five patients. Ten patients operated for endometrial hyperplasia/polyp had leiomyoma and endometrial polyp (4 each) and a case of endometrial carcinoma. Our clinical indication for hysterectomy was similar to the histopathological diagnosis in $373(86.94 \%)$ patients and rest $56(13.05 \%)$ patients had different histopathological diagnosis.

Most of the patients operated for adnexal mass had ovarian pathology $(\mathrm{n}=190,91.78 \%)$. Mature cystic teratoma $(\mathrm{n}=74,35.74 \%)$, endometriosis $(\mathrm{n}=38,18.35 \%)$, serous cystadenoma $(n=20,9.66 \%)$ and haemorrhagic cyst $(n=22$, $10.6 \%$ ) were the most common histopathological findings in the adnexal mass, also $10(4.83 \%)$ of them had 
malignancy (ovarian carcinoma $=9$, metastatic carcinoma=1) (Table 5). There were 112 patients requiring hysterectomy for AUB after failed medical management and in these patients leiomyoma $(n=59,52.68 \%)$ was the most common histopathological finding followed by adenomyosis $(\mathrm{n}=41,36.61 \%)$. Mature cystic teratoma $(n=12,24.49 \%)$ was also the commonest histological finding in the patients operated for abdominopelvic mass, followed by leiomyoma $(n=8,16.33 \%)$. Also there were six $(12.24 \%)$ cases of malignancy in abdominopelvic mass. Finally, after analysing the clinical diagnosis and histopathological findings, $70(8.73 \%)$ patients either did not have significant histological findings (chronic cervicitis $=2$, cervical intraepithelial neoplasia-CIN $\mathrm{II} / \mathrm{III}=4$ ) or hysterectomy could have been avoided by conservative approach (endometritis $=10$, para tubal cyst $=11$, endometrial polyp $=5$, haemorrhagic cyst $=28$ and others $=10$ ).

Table 1: Types of hysterectomy in different age-group.

\begin{tabular}{|c|c|c|c|c|c|c|}
\hline \multirow{2}{*}{\multicolumn{2}{|c|}{ Variants }} & \multicolumn{4}{|c|}{ Type of hysterectomy } & \multirow[b]{2}{*}{ Total (\%) } \\
\hline & & ТАН (\%) & TAH+B/L & ngectomy (\%) & TAH+BSO (\%) & \\
\hline \multirow{7}{*}{ Age } & $\leq 30$ & 1 & 3 & & 4 & $8(1)$ \\
\hline & $31-40$ & 10 & 86 & & 98 & $194(24.22)$ \\
\hline & $41-50$ & 3 & 59 & & 345 & $407(50.81)$ \\
\hline & $51-60$ & 0 & 1 & & 137 & $138(17.23)$ \\
\hline & $61-70$ & 0 & 0 & & 44 & $44(5.49)$ \\
\hline & $71-80$ & 0 & 0 & & 9 & $9(1.12)$ \\
\hline & $\geq 80$ & 0 & 0 & & 1 & $1(0.12)$ \\
\hline \multicolumn{2}{|c|}{ Total (\%) } & $14(1.75)$ & 149 (18.6) & & $638(79.65)$ & 801 \\
\hline \multirow{6}{*}{$\begin{array}{l}500 \\
400 \\
300\end{array}$} & & & & & & 391 \\
\hline & & & & & & \\
\hline & & & 207 & & & \\
\hline & & & & 112 & & \\
\hline & 49 & 28 & & & 14 & \\
\hline & $\begin{array}{c}\text { Abdominopelvic } \\
\text { Mass }\end{array}$ & Adenomyosis & Adnexal Mass & AUB & others & Fibroid \\
\hline
\end{tabular}

Figure 1: Indication for abdominal hysterectomy.

Table 2: Intraoperative and post-operative variables.

\begin{tabular}{|lll|}
\hline Variables & No. of patients $(\mathbf{n}=\mathbf{1 1 3 1})$ & Percentage \\
\hline Intraoperative & 9 & 1.12 \\
\hline Bowel injury & 4 & 0.5 \\
\hline Bladder injury & $80.37 \pm 27$ SD & \\
\hline Operative time (min) & & \\
\hline Postoperative & $3.55 \pm 3$ SD & 1.12 \\
\hline Hospital stay (days) & 9 & 0.25 \\
\hline Wound infection & 2 & 0.1 \\
\hline Chest infection & 1 & \\
\hline Mortality & & \\
\hline
\end{tabular}

Table 3: Histopathological diagnosis of hysterectomy specimen.

\begin{tabular}{|llc|}
\hline Variants & Total no. of patients $(\mathbf{n = 8 0 1})$ & Percentage \\
\hline Leiomyoma & 436 & 54.43 \\
\hline Benign ovarian tumour & 210 & 26.22 \\
\hline Mature cystic teratoma & 87 & \\
\hline Haemorrhagic cyst & 28 & \\
\hline
\end{tabular}




\begin{tabular}{|lll|}
\hline Variants & Total no. of patients $(\mathbf{n}=\mathbf{8 0 1})$ & Percentage \\
\hline Endometriosis & 41 & \\
\hline Mucinous cystadenoma & 11 & 11.49 \\
\hline Serous cystadenoma & 27 & 1.25 \\
\hline Others & 16 & 3.5 \\
\hline Adenomyosis & 92 & 3.12 \\
\hline Endometritis & 10 & \\
\hline Others & 28 & \\
\hline Malignancy & 25 & \\
\hline Ovarian carcinoma & 15 & \\
\hline Others & 10 & \\
\hline
\end{tabular}

Table 4: Histopathological diagnosis of patients operated for fibroid uterus.

\begin{tabular}{|lll|}
\hline Variants & Total no. of patients $(\mathbf{n}=\mathbf{3 9 1})$ & Percentage \\
\hline Leiomyoma & 350 & 89.51 \\
\hline Adenomyosis & 24 & 6.1 \\
\hline Malignancy & 7 & 1.7 \\
\hline Haemorrhagic cyst & 2 & 0.51 \\
\hline Others & 8 & 2.04 \\
\hline
\end{tabular}

Table 5: Histopathology of the patients operated for adnexal mass.

\begin{tabular}{|lll|}
\hline Variants & Total no. of patients $(\mathbf{n}=\mathbf{2 0 7})$ & Percentage \\
\hline Benign ovarian disease & & 35.75 \\
\hline Mature cystic teratoma & 74 & 18.36 \\
\hline Endometriosis & 38 & 9.66 \\
\hline Serous cystadenoma & 20 & 10.63 \\
\hline Haemorrhagic cyst & 22 & 5.31 \\
\hline Para tubal cyst & 11 & 7.72 \\
\hline Others & 16 & 4.8 \\
\hline Malignancy & 10 & 4.83 \\
\hline Leiomyoma & 10 & 0.96 \\
\hline Adenomyosis & 2 & 2.41 \\
\hline Others & 5 & \\
\hline
\end{tabular}

\section{DISCUSSION}

Hysterectomy is one of the most common gynaecological surgery performed worldwide. There are various approaches for hysterectomy, but abdominal hysterectomy is still the most common route, though recently there has been rise and preference towards vaginal and laparoscopic hysterectomy. ${ }^{9,10,16,17}$ Abdominal hysterectomy ( $\mathrm{n}=801$, $70.8 \%$ ) was also the most common approach in our institute. The means age of these patients was $46.45 \pm 8.39$ SD years and the maximum number of hysterectomy was done in the age group between 41-50 years $(\mathrm{n}=407,50.81 \%)$, which was similar to other studies and study from US, where $78.3 \%$ of the patients were less than 55 years. ${ }^{3,16,18}$

Fibroid uterus was the most common indication for hysterectomy ( $\mathrm{n}=391,48.81 \%$ ), followed by adnexal mass and abnormal uterine bleeding. These three were the major indications $(\mathrm{n}=710,88.63 \%)$ for abdominal hysterectomy in our study. Fibroid uterus is the most common indication for hysterectomy worldwide except in few countries like Canada, where dysfunctional uterine bleeding (DUB) is the most common indication for hysterectomy. ${ }^{1,8,10}$ Pelvic organ prolapse, AUB, adenomyosis and ovarian tumours were the other common indication for hysterectomy. ${ }^{11,16,19}$ Pelvic organ prolapse is the second most common indication for hysterectomy in the developing countries and its incidence in the developed countries has been decreasing. ${ }^{11,20}$ Pelvic organ prolapse though is common in our institute, our approach in mainly vaginal route and not the abdominal, though there are studies with success rate as high as $94.7 \%$ by vaginal route for well selected patients. ${ }^{9}$ Although the vaginal hysterectomy has been recommended as the most appropriate route, it is not always feasible in all the patients, and hence there has been increasing trend towards minimal invasive hysterectomy. 4,9,21 Abdominal hysterectomy carries highest complication rate varying from $10.9 \%$ to $26.4 \%$, which is much higher than we experienced $(n=26$, $3.24 \%){ }^{11,12,16}$ Having said so, VH is not always feasible and laparoscopic approach is technically demanding and 
costly, hence abdominal hysterectomy is preferred by most in the literature, as seen in this study, where abdominal hysterectomy was our preferred $(\mathrm{n}=801,70.8 \%)$ route. ${ }^{11,14,16,19}$

The most common histopathological finding in our study were leiomyoma, benign ovarian tumour and adenomyosis, and these three were accounted for 738 $(92.13 \%)$ specimen analysed, which was similar to the other studies. ${ }^{22,23}$ In the study by Rai et al ovarian disease $(80.3 \%)$ was the most common cause for adnexal mass which was similar to our study $(91.78 \%)$ and mature cystic teratoma was the most common histopathological finding in both adnexal and abdominopelvic mass. ${ }^{24}$ There were 112 patients $(13.98 \%)$ present with abnormal uterine bleeding requiring hysterectomy for failed medical management. Leiomyoma and adenomyosis were the most common (89.28\%) histopathological finding in those AUB patients, similar to the study by Sawke et al where adenomyosis followed by leiomyoma was the common cause. $^{25}$

Hysterectomy like any other surgery is associated with complications and also is it the organ of self-being for women, both of which is the cause of dissatisfaction. Hence, the reason for hysterectomy should always be justified. Broder et al evaluated the appropriateness of recommendations for hysterectomies done for benign disease and revealed that $70 \%(n=367)$ of hysterectomies didn't meet the level of care of recommendation by the expert panel. ${ }^{15}$ This finding raised an eyebrow on the need of hysterectomy, and that actually there may be misuse or overused of hysterectomy. We found that in $731(91.26 \%)$ patients, there was histopathological evidence for need of hysterectomy, this was similar to the study where hysterectomy was justified in $91.37-98.9 \%$ patients. ${ }^{16,20}$ There are different organ preserving options including myomectomy, embolization (fibroid or uterine artery), endometrial ablation, polypectomy and so on. ${ }^{5,17}$ Depending on the disease pattern, facility and expertise availability these organ-preserving options should be explored rigorously before opting for hysterectomy. We believe that, in our study $70(8.73 \%)$ hysterectomies could have been avoided because some of these patients didn't have significant pathology on histopathological examination and in other, the disease might have been amendable to the organ preserving surgery. However, it is necessary to emphasize that twenty-five $(3.12 \%)$ patients whom we had operated for benign disease turnout to have malignancy on histopathological examination, so wherever there is high index of suspicion, hysterectomy may be justified.

\section{CONCLUSION}

Hysterectomy is the second most common surgery in the women and abdominal hysterectomy is the commonest approach. Leiomyoma is the most common indication for hysterectomy and mature cystic teratoma is the most common ovarian pathology. The clinical indication for hysterectomy correlate with most of the histopathological specimen but the hysterectomy should be done only when all the other organ-sparing option fails. However, there should not be hesitation to opt it as the initial choice when there is high index of clinical suspicion for malignancy.

\section{ACKNOWLEDGMENTS}

Authors would like to thank all the patients, colleagues and faculties, and staffs for their generous support.

\section{Funding: No funding sources}

Conflict of interest: None declared

Ethical approval: The study was approved by the Institutional Ethics Committee

\section{REFERENCES}

1. Liu F, Pan Y, Liang Y, Zhang C, Deng Q, Li X, et al. The epidemiological profile of hysterectomy in rural Chinese women: A population-based study. BMJ Open. 2017;7(6):1-9.

2. Wiser A, Holcroft CA, Tulandi T, Abenhaim HA. Abdominal versus laparoscopic hysterectomies for benign diseases: Evaluation of morbidity and mortality among 465,798 cases. Gynecol Surg. 2013;10(2):117-22.

3. Morgan DM, Kamdar NS, Swenson CW, Kobernik EK, Sammarco AG, Nallamothu B. Nationwide trends in the utilization of and payments for hysterectomy in the United States among commercially insured women. Am J Obstet Gynecol. 2018;218(4):425:1-425.

4. Committee on Gynecologic Practice. Committee Opinion No 701: Choosing the Route of Hysterectomy for Benign Disease. Obstet Gynecol. 2017;129(6):155-9.

5. Neis KJ, Zubke W, Fehr M, Römer T, Tamussino K, Nothacker M. Hysterectomy for Benign Uterine Disease. Dtsch Arztebl Int. 2016;113(14):242-9.

6. Lykke R, Blaakær J, Ottesen B, Gimbel H. The indication for hysterectomy as a risk factor for subsequent pelvic organ prolapse repair. Int Urogynecol J. 2015;26(11):1661-5.

7. Shekhar C, Paswan B, Singh A. Prevalence, sociodemographic determinants and self-reported reasons for hysterectomy in India. Reprod Health. 2019;16(1):1-16.

8. Toma A, Hopman WM, Gorwill RH. Hysterectomy at a Canadian tertiary care facility: Results of a one year retrospective review. BMC Womens Health. 2004;4:2-8.

9. Kovac SR. 28 Years of Using Hysterectomy Guidelines to Determine the Feasibility of Vaginal Hysterectomy. Gynecol Obstet. 2015;6(4).

10. Driessen SRC, Baden NLM, van Zwet EW, Twijnstra ARH, Jansen FW. Trends in the Implementation of Advanced Minimally Invasive Gynecologic Surgical Procedures in The Netherlands. J Minim Invasive Gynecol. 2015;22(4):642-7. 
11. Mäkinen J, Brummer T, Jalkanen J, Heikkinen A-M, Fraser J, Tomás E, et al. Ten years of progressimproved hysterectomy outcomes in Finland 19962006: a longitudinal observation study. BMJ Open. 2013;3(10):003169.

12. Leung PL, Tsang SW, Yuen PM, Quality Assurance Subcommittee in Obstetrics and Gynaecology, Hospital Authority HK. An audit on hysterectomy for benign diseases in public hospitals in Hong Kong. Hong Kong Med J - Xianggang yi xue za zhi. 2007;13(3):187-93.

13. Makinen J. Morbidity of 10110 hysterectomies by type of approach. Hum Reprod. 2001;16(7):1473-8.

14. Wright JD, Herzog TJ, Tsui J, Ananth C V., Lewin $\mathrm{SN}, \mathrm{Lu} \mathrm{YS}$, et al. Nationwide trends in the performance of inpatient hysterectomy in the United States. Obstet Gynecol. 2013;122(2 Pt 1):233-41.

15. Broder MS, Kanouse DE, Mittman BS, Bernstein SJ. The appropriateness of recommendations for hysterectomy. Obstet Gynecol. 2000;95(2):199-205.

16. Pandey D, Sehgal K, Saxena A, Hebbar S, Nambiar J, Bhat RG. An Audit of Indications, Complications, and Justification of Hysterectomies at a Teaching Hospital in India. Int J Reprod Med. 2014;1-6.

17. American College of Obstetricians and Gynecologists. ACOG committee opinion no. 557: Management of acute abnormal uterine bleeding in nonpregnant reproductive-aged women. Obstet Gynecol. 2013;121(4):891-6.

18. Yadav DP, Yadav R, Bhati I. Abdominal hysterectomy: analysis of clinico-histopathological correlation in Western Rajasthan, India. Int J Reprod Contracept Obstet Gynecol. 2017;6(3):1012.

19. Titloye NA, Duduyemi BM, Asiamah EA, Okai I, Ossei PPS, Konney TO, et al. Total abdominal hysterectomy in a Tertiary Hospital in Kumasi. J Med Biomed Sci. 2018;7:22-8.

20. Vaidya S, Vaidya SA. Patterns of lesions in hysterectomy specimens in a tertiary care hospital. J Nepal Med Assoc. 2015;53(197):18-23.

21. Sandberg EM, Hehenkamp WJK, Geomini PM, Janssen PF, Jansen FW, Twijnstra ARH. Laparoscopic hysterectomy for benign indications: clinical practice guideline. Arch Gynecol Obstet. 2017;296(3):597-606.

22. Sharma C, Sharma M, Raina R, Soni A, Chander B, Verma S. Gynecological diseases in rural India: A critical appraisal of indications and route of surgery along with histopathology correlation of 922 women undergoing major gynecological surgery. J Midlife Health. 2014;5(2):55-61.

23. Shergill SK, Shergill HK, Gupta M, Kaur S. Clinicopathological study of hysterectomies. J Indian Med Assoc. 2002;100(4):238-9.

24. Rai R, Bhutia PC, Tshomo U. Clinicopathological profile of adnexal masses presenting to a tertiary-care hospital in Bhutan. South Asian J cancer. 2019;8(3):168-72.

25. Sawke NG, Sawke GK, Jain H. Histopathology findings in patients presenting with menorrhagia: A study of 100 hysterectomy specimen. J Midlife Health. 2015;6(4):160-3.

Cite this article as: Manandhar T, Sitaula S, Thapa BD, Agrawal A. Clinicopathological correlation of abdominal hysterectomy. Int J Reprod Contracept Obstet Gynecol 2020;9:4361-6. 